\title{
TRADUÇÃO INTERSEMIÓTICA DE LITERATURA INFANTO-JUVENIL: VIVÊNCIAS EM SALA DE AULA
}

\author{
Neiva de Aquino Albres* \\ Universidade Federal de Santa Catarina
}

\begin{abstract}
Resumo: Nos últimos anos, houve crescimento de Literatura infanto-juvenil e grande incentivo à educação bilíngue para surdos, propiciando a abertura para a tradução de obras em português para a Libras. Como consequência direta desse fenômeno, houve mudança significativa na compreensão de como se traduzir materiais multimodais. Com isso, o objetivo principal deste artigo é discutir/analisar episódios (vídeo gravação) que focalizaram a mediação da professora-pesquisadora, em contextos de trabalho de tradução dos alunos, no intuito de verificar quais são as mudanças na construção dos sentidos segundo os textos apresentados nesses materiais, sob a luz da Análise de Discurso (BAKHTIN, 1999). Sugere-se que esse tipo de atividade, de tradução coletiva, possa ser desenvolvida com alunos de tradução, de tal modo que ela forneça condições para que os alunos, ao traduzir o texto multimodal, possam se conscientizar da complexidade e da especificidade das escolhas linguísticas e discursivas envolvidas no processo tradutório.
\end{abstract}

Palavras-chave: Tradução de literatura infanto-juvenil. Multimodalidade. Texto multimodal. Formação de tradutores. Tradução em grupo. Pedagogia da tradução.

\footnotetext{
* Doutora em Educação Especial. Docente e pesquisadora da Universidade Federal de Santa Catarina - UFSC no departamento de Língua Brasileira de Sinais LIBRAS. Líder do grupo de Pesquisa Didática e ensino de tradutores e intérpretes de línguas de sinais - DETILS e membro do Grupo de Pesquisa em Interpretação e Tradução de Línguas de Sinais - InterTrads. Florianópolis, Santa Catarina, Brasil. Email: neiva.albres@ufsc.br
} 


\title{
INTERSEMIOTIC TRANSLATION OF LITERATURE FOR CHILDREN AND YOUTH: EXPERIENCES IN CLASSROOM
}

\begin{abstract}
In recent years, there was growth of children's literature and great incentive to bilingual education for deaf providing the opening for the translation of works in Portuguese language to Brazilian sign language. As a direct consequence of this phenomenon, significant change in the understanding of how to translate multimodal materials. For this reason, the main goal of this article is to discuss/analyze episodes (video-recorded) which focused on the mediation of the teacher-researcher in translation work contexts of the students, in intention to verify what are the changes in the construction of the meanings in texts presented in these materials, according to the directions of Discourse Analysis (BAKHTIN, 1999). It is suggested that these activities may be carried out with translation students, in such a way that they enable students, while they translate multimodal text, to become aware of the complexity and specificity of the linguistic and discoursive choices involved in the process of translation.

Keywords: Children literature translation. Multimodality. Multimodal text. Translator training. Group translation. Translation pedagogy.
\end{abstract}

\section{Introdução}

A formação dos tradutores esteve marcadamente traçada para as letras, para o foco no texto escrito, sem ater-se a outros aspectos que envolvem a leitura e a construção de sentidos. Mesmo quando da discussão de atuação e de formação de intérpretes que estão, eminentemente, envolvidos de interações face a face, 0 tratamento que se dá é essencialmente relacionado à estrutura linguística escrita. Todavia, atualmente, não há como se discutir tradução desvinculada dos aspectos multifacetados e multimodais da linguagem humana, principalmente quando do trabalho com o gênero literatura infanto-juvenil.

O uso de diferentes recursos semióticos começou a ser empregado nos meios comunicativos e, gradualmente, passou a partilhar com os recursos verbais, outrora dominantes, a comu- 
nicação de informações essenciais dos textos contemporâneos (LEMKE, 1998).

Contudo, congregar o verbal e o não verbal em material impresso para crianças e jovens sempre foi algo mais comum que em outros tipos de materiais, em que o visual permanecia praticamente invisível até começar a ser amplamente explorado pelas tecnologias computacionais e surgir realçado em diferentes contextos (FERNANDES, 2013).

Atualmente, a literatura infanto-juvenil vem assumindo configurações específicas nos diversos meios em que se materializa, os quais oferecem às crianças e aos jovens leitores surdos diferenciados modos de interação com o material literário, agregando, geralmente, o vídeo em língua de sinais sobreposto à imagem do livro (ALBRES, 2014).

Traduções de literatura infanto-juvenil para línguas de sinais requerem mais ainda o uso de interfaces tridimensionais e digitais que contribuam para a leitura da expressão em sinais por meio de vídeo. Iniciativas neste sentido podem ser vislumbradas com o projeto Argentino "Videolibros Virtuales" ${ }^{1}$, disponibilizado em site em que adultos leem livros em língua argentina de sinais (Lengua de Señas Argentina - LSA), organizado pela Confederação Argentina de Surdos (CAS) e o projeto "Bilingual Storybook App" 2 , nos Estados Unidos da América, da Universidade Gallaudet, com o projeto da Fundação Científica Nacional de aprendizagem visual (Visual Learning - VL2). No Brasil, a Editora Arara Azul tem trabalhado com a tradução cultural de literatura, traduzindo os clássicos para a língua brasileira de sinais - Libras, contribuindo com o Ministério da Educação Brasileiro no projeto de distribuição de materiais bilíngues para as escolas que tenham alunos surdos matriculados.

Os projetos acima descritos apresentam materiais bilíngues e têm como objetivo contribuir para o aprendizado e experiência leitora de crianças surdas, apresentando uma pessoa real usando a língua de sinais de cada país, animação e acompanhamento do texto escrito na língua do país, envolvendo aspectos de leitura, tradução e contação da história (ALBRES, 2014). 
Interessa-nos discutir sobre o trabalho com gênero literatura infanto-juvenil no processo de formação de tradutores (Libras/ Português). Seguramente, cumpre a nós, estudiosos da tradução, refinar o olhar para uma investigação do diálogo que na literatura se estabelece do texto com as ilustrações, com o design do material, com a Libras compondo um produto multimodal e todo o processo dialógico que se requer para uma produção que congregue tantas linguagens.

Compreendendo a complexidade desse objeto de estudo, que requer uma visão multidisciplinar da tradução em sua articulação com a educação, linguística e tecnologia, procuramos evidenciar que novas configurações estéticas estão emergindo e que os tradutores de Português e Libras não podem se furtar dessas configurações contemporâneas. Como promover atividades de formação de tradutores que congreguem alunos em diferentes níveis linguísticos e competências tradutórias? Como trabalhar com tradução intersemiótica de literatura infanto-juvenil em sala de aula de forma coletiva?

Importa desvelar mediações necessárias, na esfera formativa, para que tradutores Português/Libras sejam sensíveis e competentes para trabalhar com este gênero textual. Numa época em que a confluência de linguagens configura novas narrativas e os meios eletrônicos e a realidade virtual corporificam diferentes formas de interagir com as obras de arte, literárias ou não, uma reflexão sobre tais temas se torna necessária, sobretudo para compreendermos a atuação de tradutores com esse tipo de material e as ferramentas que dispomos para desenvolver uma tradução criativa de texto de literatura infanto-juvenil.

Assim, este artigo é um espaço para sistematizarmos nossas reflexões, proporcionando um diálogo profícuo entre linguística, literatura, tradução, educação e tecnologia, não só pela linguagem multimodal, mas essencialmente multidisciplinar. 


\section{Formação de tradutores e intérpretes de libras}

Intensifica-se a discussão da necessidade de formação do tradutor e do intérprete de Libras e de Português - TILSP com a inclusão de alunos surdos em salas de aula do ensino regular a partir da proposta de Educação inclusiva e se produz diretrizes para sua formação. Desta forma, a formação de intérpretes de Libras tem sido emergencial no contexto de educação inclusiva. O decreto $5.626 / 2005$ prevê a formação desse profissional por meio de cursos de extensão, graduação em Letras Libras e/ou em cursos de pós-graduação, organizados em instituições educacionais.

Diferentes cursos de formação têm surgido no Brasil, mas o contorno didático que explore os diferentes gêneros textuais e discutam sobre a multimodalidade envolvida na linguagem contemporânea precisa ser amadurecido entre os formadores.

Alves, Magalhães e Pagano (2007, p.7) também questionam a falta de consenso na formação de tradutores:

A ideia de levar o tradutor em formação a desenvolver estratégias de tradução está imbuída do espírito de conscientizá-lo da complexidade do processo tradutório e da necessidade de monitorar suas ações e examinar com cuidado as decisões tomadas ao longo do processo tradutório. A conscientização deste tradutor envolve um redimensionamento do conceito de aprender, o qual passa a demandar que o aprendiz se torne diretamente responsável pelo seu próprio processo de aprendizagem. Em outras palavras, espera-se que o aprendiz se torne autônomo para escolher o caminho mais adequado, para selecionar e gerenciar as ações que melhor respondam a seus interesses e necessidades e para buscar formas de apreensão e utilização de conhecimentos que sejam mais apropriadas ao seu estilo individual de aprendizagem. (ALVES; MAGALHÃES; PAGANO, 2000, p. 7). 
A formação de TILSP requer que se contemple "a dimensão discursiva da linguagem, isto é, seu uso concreto, possibilitando aos aprendizes uma reflexão sobre os processos de construção de sentidos a partir das situações concretas de enunciação" (ALBRES; NASCIMENTO, 2014, p. 226).

Há necessidade de vivencias de tradução orientada, tradução coletiva, revisão de traduções, análise de traduções, todas essas ações pedagógicas mediadas pela linguagem. A cada novo contexto e gênero textual o tradutor é desafiado a lidar com distintos aspectos. Neste trabalho, focaremos no texto de literatura infanto-juvenil e a perspectiva que se apresenta é baseada nos princípios da abordagem histórico-cultural (FONTANA, 2000) e enunciativo-discursiva (BAKHTIN, 1999). Assim,

o diálogo é a maneira criativa e produtiva do eu se aproximar com suas palavras às palavras do outro, construindo uma compreensão que, por não ser de mero reconhecimento dos signos usados, é sempre uma proposta, uma oferta, uma resposta aberta a negociação e a novas construções. (GERALDI, 2013, p.15).

Desta forma, a prática pedagógica de formação de tradutores e de intérpretes constitui-se o fio condutor deste texto. Para isso, consideramos importante, primeiramente, incursionar o leitor na discussão teórica já existente sobre multimodalidade, a partir de estudiosos, principalmente, da área de Estudos da Tradução e Educação. Por fim, discutiremos o papel do tradutor diante de textos multimodais.

\section{Multimodalidade e multidisciplinariedade nos Estudos da Tradução}

Os Estudos da Tradução é um campo disciplinar constituído de diferentes subáreas que estudam a tradução a partir de múltiplas 
abordagens. Nesta perspectiva, a área é caracterizada pela interdisciplinaridade, conforme pode ser visualizada em distintos mapeamentos (VASCONCELLOS, 2010). Com o advento dos Estudos da tradução, pesquisas que têm como objetivo analisar traduções literárias são mapeadas como "Estudos literários", classificadas inicialmente por James S.Holmes (1972) como um tema chave. A inclusão de textos populares nestes estudos ocasiona uma revolução que propicia a mudança de nome da área, sendo denominada de "Estudo comparado" (AGUIAR, 2000). Criada no Brasil a associação de literatura comparada em 1986 (ABRALIC, 1991). Todavia, a tradução de literatura infanto-juvenil foi por muitos anos desprestigiada, principalmente, no campo científico, considerada, marginalmente, como um tipo de texto de menor valor cultural e social, sendo que só recentemente ganhou espaço nos estudos da tradução (AZENHA JUNIOR, 2008).

Contemporaneamente, o estudo da tradução de literatura ganhou destaque com o advento da abordagem descritiva (AGUIAR, 2000). Assim, a tradução passa a ser estudada, voltada ao produto, ou seja, o texto traduzido como também o estudo voltado ao processo, isto é, ao ato tradutório e às etapas de trabalho das quais esse texto resulta. Podemos considerar que essa classificação é didática, pois um produto está envolvido de diversas influências e o processo requer compreender as variáveis e os tipos de conhecimentos envolvidos, por isso mesmo os Estudos da Tradução configura-se por definição como um campo interdisciplinar.

Além da delimitação dos campos de estudos, os "Estudos da tradução" passa por grandes transformações em seus fundamentos, inicialmente pautados em 'abordagens linguísticas e cognitivas', chamadas de concepções tradicionais, essencialistas ou linguístico-cientificistas. Após a segunda metade do século XX, apareceram teorias menos associadas à visão linguística, reunidas sob o rótulo de perspectivas contemporâneas (SILVA, 2011). Desta forma, amplia-se a visão para aspectos sociais, culturais, econômicos, ideológicos e discursivos da tradução. 
Segundo Campos (1986, p. 27-28), “não se traduz afinal de uma língua para outra, e sim de uma cultura para outra; a tradução requer assim [...] um repositório de conhecimentos gerais, de cultura geral, que cada profissional irá [...] ampliando e aperfeiçoando [...]". O conceito de tradução vai se ampliando com o desenvolvimento das pesquisas e de diferentes fundamentações epistemológicas, incorporando as questões culturais e sociais, além das questões linguísticas que já tinham destaque nos estudos descritivos, como dito.

Incluindo que o processo de tradução requer do profissional a compreensão e a produção de um novo texto, autores indicam que a tradução é uma leitura e uma reescritura, reconhecendo a autoria do texto traduzido (ARROJO, 2004; VENUTI, 2002). O tradutor é considerado um leitor em especial e a tradução uma reenunciação (SOBRAL, 2008; SILVA, 2011). Desse modo, "cada tradução de um texto marcará também suas diferenças, pois será resultado de novas condições de produção de discurso, de diferentes relações de sentido" (MITTMANN, 1999, p. 226).

Assim, a tradução não deve ser vista como mera reprodução, mas como um texto que transforma o texto estrangeiro, em razão de diferenças linguísticas e culturais, o que pode gerar diferentes funções para o texto traduzido na cultura de chegada (BASSNETT, 2003).

Os livros de literatura infanto-juvenil têm uma especificidade: a riqueza visual de suas produções. Geralmente, congregam ilustrações e um projeto gráfico específico que acompanham a narrativa textual e colaboram significativamente para a construção de sentidos, nos ensinando a ler uma multiplicidade de linguagens simultaneamente.

\section{A leitura do tradutor para além do texto como escrita}

A partir dos anos 1990, a área da análise do discurso vem englobando a tradução como objeto de estudo, favorecendo o campo pelas interfaces de trabalho, porque traz a visão de que traduzimos 
muito mais do que palavras. Conforme Sobral (2008, p.57), "traduzimos discursos, no sentido de que a palavra não existe no vazio, ela somente existe e significa dentro de um contexto específico". E esses discursos são envolvidos de contextos e de intencionalidades, de leituras (interpretações) marcadas por questões ideológicas e subjetivas, outrora desconsideradas nos "Estudos da Tradução". Assim, os estudos passam a considerar dimensões semióticas e pragmáticas da tradução.

Compreendendo a linguagem como um trabalho para além do texto, numa abordagem ampla das relações dialógicas, estas são possíveis também entre outros fenômenos conscientizados desde que estes estejam expressos numa matéria sígnica. Por exemplo, as relações dialógicas são possíveis entre imagens de outras artes, mas essas relações ultrapassam os limites da metalinguística. (BAKHTIN, 2010, p. 184).

Bakhtin inaugura uma discussão importante no campo do estudo da linguagem, ampliando o debate para além da matéria verbal (texto escrito ou falado) de cunho linguístico. Mesmo porque, a produção de textos associada a outros elementos visuais, como ilustrações, design, forma do texto, são cada vez mais comuns e passíveis, exigem ser lidos a fim de interpretarmos de forma adequada 0 todo discursivo. Essa perspectiva "abrange as noções de discursos multimodais e multivozeados e chama a atenção para as camadas de sentido social no discurso" (MAGALHAES, 2009, p.22).

Este ponto é fundante em uma tradução, uma vez que não podemos perder de vista que os tradutores devem ser capazes de ler as múltiplas linguagens com que convivem, principalmente no estudo via gêneros, com exemplares de textos autênticos, permeados por imagens, amplamente usados em nossa sociedade, em diferentes mídias como, por exemplo: internet, revistas, jornais e televisão; em textos publicitários, informativos e literários. Assim, 
[...] as linguagens em geral, ainda hoje e especialmente hoje, aí incluídas a linguagem verbal, as visuais e as que combinam o verbal e o visual para os mais diferentes fins, implicam a mobilização de múltiplos sentidos, múltiplos discursos, criando uma interação envolvente, sedutora, viva, que atinge o homem, sua maneira de ver o mundo, sua condição de ser e estar nesse mundo. (BRAIT, 2004, p. 193).

As imagens, além de transmitir mensagens (informações), fundem-se a nossa significação e possibilitam a construção de sentidos próprios, revisitando a produção cultural de nós como o outro, do autor (escritor) e do ilustrador (desenhista). "Tanto a linguagem verbal quanto a visual são acionadas de forma a provocar a interpenetração e consequente atuação conjunta" (BRAIT, 1996, p. 65-66).

Estudos de análise do discurso buscam a "interpretação das formas de produção de sentido e efeitos de sentido de textos cuja marca principal é a constitutiva relação verbo-visual ${ }^{3}$, ou seja, a articulação entre a dimensão linguística - oral ou escrita - e a imagem" (BRAIT, 2013, p. 43).

Nos Estudos da tradução, a análise de textos, para além da escrita, são focados depois dos anos de 1990. Roman Jakobson inicia esta discussão com base em estudos intersemióticos. Dentre os tipos de tradução, diz: "Tradução intersemiótica ou transmutação consiste na interpretação de signos verbais por meio de sinais de sistemas de signos não-verbais" (JAKOBSON, 1972, p. 65). Ainda não se atem à coocorrência de múltiplas linguagens em um mesmo material, o que requer a mistura entre os diversos tipos de tradução, contudo a contrapõe à tradução interlingual (entre línguas) e à tradução intralingual (diferentes registros da mesma língua). Essa é uma importante iniciativa no campo dos Estudos da Tradução, pois introduz sistemas não verbais como materializações passíveis de serem traduzidas. A partir desta discussão, amplia-se a visão, considerando que a imagem (sistema de signo não verbal) e o texto (sistema de signo verbal) complementam um ao outro e dependem muitas vezes um do outro. 
Katharina Reiss apresenta, ainda em 1990, sua tipologia de textos, empregando os termos 'multimedial', 'multimodal' e 'multisemiotic' (termos em inglês) para se referir a textos que possuem características visuais e textuais, o último termo é usado principalmente por influencia dos Estudos Culturais e pós-modernos (SNELL-HORNBY, 2006, p. 84-85). Em síntese, são introduzidos quatro tipos de textos que dependem de elementos não-verbais, são eles:

1. texto multimidial (em Inglês geralmente usa-se audiovisual) são transmitidos pelos meios de comunicação técnica e / ou eletrônica que envolve tanto a visão quanto o som (por exemplo, material para cinema ou televisão, legenda ${ }^{4}$ e $s u b /$ surtitling);

2. texto multimodal envolve diferentes modos de expressão verbal e não-verbal, que compreende tanto a visão e som, como no teatro e ópera;

3. texto multissemiótico usa diferentes sistemas de signos gráfico, verbais e não-verbais (por exemplo, quadrinhos ou anúncios impressos, [...],

4. texto audiomidial são aqueles escrito para serem falados, portanto, para atingir o seu destinatário final por meio da voz humana e não a partir da página impressa (por exemplo, discursos políticos, comunicações orais - trabalhos acadêmicos). (SNELL-HORNBY, 2006, p. 85 - tradução nossa). ${ }^{5}$

Nessa classificação ainda predomina a ambivalência entre verbal e não verbal e com pouco detalhamento do aspecto não verbal, como também pouco relacionado com o corpo de quem enuncia, com os gestos e com os ambientes e contextos discursivos. Ponderamos que, com o uso de interfaces tridimensionais e digitais, é comum materiais híbridos que congregam diversas linguagens, mesclando todos os tipos textuais descritos por Snell-Hornby (2006). 
Dentre esses tipos, Snell-Hornby (2006) considera a literatura infanto-juvenil como um tipo de texto multisemiótico, pois possibilita a comunicação por meio de elementos visuais e de elementos textuais, e que, ao se realizar a tradução deste tipo de texto, tem-se que levar em conta não só os elementos linguísticos, mas também os elementos gráficos e visuais. Vale destacar que a autora faz essa descrição baseada em materiais impressos (livros), contudo os E-books interativos atuais (em suportes digitais em forma de aplicativos para tablets e e-readers) trazem uma complexa linguagem híbrida que requer que se ampliem os estudos deste gênero.

Snell-Hornby (1988) ressalta que as traduções desempenham um papel primário, criativo e inovador no âmbito do sistema literário. Assim, para a autora, a tradução é vista como essencialmente um tipo de texto por direito próprio, como parte integrante da cultura alvo, e não meramente como uma reprodução de outro texto.

Todo tradutor deve considerar o objetivo da tradução, o publico receptor do livro traduzido, e os efeitos dessa tradução na cultura de chegada, sensibilizar-se que as palavras lidas não estão isoladas, mas compõem um contexto e situação formativa ou de entretenimento para as crianças e jovens.

Quanto aos objetivos da tradução, Snell-Hornby (1988) afirma que:

[...] o problema não depende do próprio texto de origem, mas do significado do texto traduzido para o seu leitor como membro de uma determinada cultura, ou como um sub-grupo dentro dessa cultura, com a constelação do conhecimento, julgamento e percepção que eles têm desenvolvido a partir do texto. ${ }^{6}$ (SNELL-HORNBY,1988, p. 42 - tradução nossa).

Tradutores produzem traduções permeados pelas suas experiências como leitores, pela construção de sentidos que empregaram do material lido, de seu capital cultural e linguístico, retomando a sua 
imagem como criança e refratando sua concepção para as crianças destinatárias do material traduzido. Configura-se, então, em uma relação dialógica complexa, em que os autores, desenhistas e tradutores desempenham uma força conjunta para a materialização do livro traduzido e devem ser considerados autores de sua tarefa fim, ou seja, produção escrita, ilustração e tradução, mais que a simples integração entre verbal e não verbal.

Graças à tecnologia digital, os produtos a serem lidos estão cada vez mais complexos e o tradutor se vê entre o texto e a imagem, e entre os outros elementos na tradução multimídia. Diante desse desafio, o termo tradução é associado a outras palavras, como tradução fílmica, tradução na tela ${ }^{7}$, tradução de mídia, tradução multimídia (GAMBIER, 2008). Não há um consenso em como denominar esse tipo de tradução, mas o autor complementa que: "ao mesmo tempo, essa indecisão terminológica pode ser um sinal de vitalidade, refletindo desenvolvimentos tecnológicos recentes"8 (p. 25).

Além dos estudos da tradução, estudos no campo da educação e linguística aplicada têm tomado a leitura de materiais multimodais como objeto de estudo e podem contribuir com a compreensão sobre o processo de leitura que os tradutores desempenham quando traduzem e de como as crianças aprendem a ler esse gênero textual em novas mídias. Assim, os processos de letramentos digitais e de leitura multimodal vêm ganhando destaque nas pesquisas sobre aprendizagem de leitura, discutindo essa intrínseca relação entre multiletramentos e multimodalidade (ROJO, 2007; SANTOS, 2008).

Outros estudos sobre processos de leitura, ainda que pautados em diferentes perspectivas, têm empregado o termo leitura multimodal (DIONÍSIO, 2014).

A tecnologia digital trouxe mudanças significativas para a escrita nos últimos 20 anos ou mais. Nos meios de comunicação impressos como jornais, panfletos ou propaganda, as palavras agora estão quase sempre acompanhadas por fotografias, diagramas ou desenhos, e a impressão é realçada por uma variedade de tamanhos e formas de fontes. As telas 
estão muito mais comuns em estabelecimentos comerciais, ambientes de trabalho, escolas e lares. Os celulares transmitem imagens e palavras, e também sons. Muitos textos cotidianos são agora multimodais, combinando palavras com imagens em movimento, som, cor e uma variedade de visuais fotográficos, desenhados ou criados digitalmente. (BEARNE; WOLSTENCROFT, 2007, p.1).

A escola precisa acompanhar os avanços da tecnologia e das formas de comunicação para além do texto propriamente dito, considerando que as redes sociais e os aplicativos de comunicação contribuem não só para a leitura, mas também para a produção de textos multimodais.

Na multimodalidade, a maioria dos textos envolve um complexo jogo entre textos escritos, cores, imagens, elementos gráficos e sonoros, o enquadramento, a perspectiva da imagem, espaços entre imagem e texto verbal, escolhas lexicais, com predominância de um ou de outro modo, de acordo com a finalidade da comunicação, sendo, portanto, recursos semióticos importantes na construção de diferentes discursos. (SANTOS, 2008, p.77-78).

Estudos no campo da educação de surdos também têm se atentado para essas contribuições contemporâneas (LODI; HARRISON; CAMPOS, 2002; REILY, 2003; GESUELY; MOURA, 2006; FIGUEIREDO; GUARINELLO, 2013). “Com os avanços da tecnologia, os recursos que se apresentam para as mídias são inúmeros e, por conseguinte, exigem certa aprendizagem multimodal, ou seja, o leitor precisa aprender a ler as palavras, imagens e sons presentes no texto, ao mesmo tempo" (FIGUEIREDO; GUARINELLO, 2013, p. 179).

Os textos possibilitam o registro de discursos. Fomentam a construção de sentidos na relação entre a leitura e outros textos, 
a partir das conexões individuais de cada leitor. A leitura é feita tanto do texto verbal quanto não verbal (diagramação, cores, ilustrações, tipo de papel). Quando da personificação da linguagem verbal por meio de tradutores para a língua de sinais, em que seus corpos compõem o projeto na tela, gestos, fluxo dos sinais, o espaço que ocupam e a interação que desenvolvem com o todo dos elementos apresentados na tela e da história são aspectos da multimodalidade.

Até o presente momento, estamos falando de gêneros escritos. Todavia, gêneros primários, como interações face-a-face, narrativas e diálogos têm sido estudados também para a compreensão da complexa relação de multimodalidade para o processo de significação.

Paralelamente aos estudos da tradução e estudos da educação, a linguística, por meio de estudos da conversa ou estudos da narrativa, busca aprofundar o conhecimento sobre os processos interativos e de enunciação em gêneros primários, considerando que no campo da linguística o estudo de textos escritos foi desenvolvido em larga escala e os estudos da interação face-a-face foi, por muito tempo, negligenciado. Interessante destacar que estes estudos apontam que as pessoas, em interação, "atuam conjuntamente criando várias camadas de significação nos seus discursos", optando por diferentes recursos verbais e não verbais - na comunicação (CLARK, 1996, p. 186 apud SILVA, 2014, p. 02), estudando a língua em uma perspectiva multimodal. Dessa forma, o termo multimodal é empregado composto por sistemas semióticos de diversas naturezas, incluindo o gesto e o contexto (SILVA, 2014).

Constatamos o uso do termo multimodal e multimodalidade para diferentes materializações, assim como o termo verbo-visual. Somos favoráveis a uma definição mais precisa, porque, a nosso ver, a expressão "verbo-visual" tem permitido ou autorizado, em alguns casos, uma compreensão do conceito de linguagem presa ao âmbito linguístico (oral ou textual), marginalizando as línguas de sinais, o que prejudica a riqueza e vicissitude desse conceito, e, no processo, paradoxalmente, deixa de dar o devido valor às formas linguísticas da Libras, equiparando-a ao não verbal (por ser de modalidade vi- 
sual), quando feita uma leitura equivocada. O termo "verbo-visual" é empregado associado a outras palavras, por exemplo: texto verbo-visual, totalidade verbo-visual, arquitetônica verbo-visual, natureza verbo-visual da linguagem (NASCIMENTO, 2011).

Verificamos, também, que a expressão "multimodal" vem sendo empregada em diferentes campos, como análise da conversa, análise de processos de letramento e para a complexidade de diversos tipos de textos e materiais. Desta forma, seu conceito toma contornos diversos e requer do leitor um esforço mental para construir sentido sobre qual perspectiva o termo multimodal é empregado. Todavia, não houve emprego, pelo que levantamos, do termo tradução multimodal, mas sim de texto multimodal - mesmo no âmbito dos Estudos da Tradução (SNELL-HORNBY, 2006)-, leitura multimodal e letramento multimodal. Quando tratamos de processos de tradução o termo comumente empregado pelos pesquisadores foi tradução intersemiótica.

De qualquer forma, o ato de ler e traduzir deve ser entendido como algo que extrapola o universo da escrita, de modo a abarcar outros códigos e suportes. Por isso, estudos mais recentes destacam a peculiaridade da multimodalidade, como sintetizado nesta parte do artigo.

\section{Metodologia: o contexto da investigação}

O presente trabalho refere-se a uma pesquisa contínua de prática pedagógica inscrita no Grupo de Pesquisa Didática e ensino de tradutores e intérpretes de línguas de sinais - DETILS. A investigação foi realizada pela autora deste trabalho - aqui denominada professora.

Caracterizada como análise de um caso, de abordagem qualitativa, a pesquisa investigou a própria prática da professora num contexto de sala de aula, com tarefas práticas de tradução coletiva. $\mathrm{O}$ recorte aqui apresentado refere-se ao trabalho com alunos do curso Letras Libras, na UFSC, no ano de 2015 - atividade compondo um minicurso na semana se Letras da UFSC, especificamente em ati- 
vidade de leitura e tradução a partir do livro "O Pequeno Príncipe" (SAINT-EXUPÉRY, 2009).

Por que a escolha da exploração de tarefa de tradução coletiva como cenário para investigação da própria prática? Avaliamos necessário ampliar sua caracterização e evidenciar a articulação de um trabalho dessa natureza com a investigação da própria prática e do ensino-aprendizagem para o tratamento de textos multimodais e do trabalho com tradução intersemiótica.

\section{Tradução de Literatura infanto-juvenil para Libras em meio digital}

Temos como objetivo conduzir os participantes do minicurso a compreender os aspectos enunciativos e discursivos da interpretação da língua de sinais e as especificidades de atuação do tradutor/ intérprete em materiais literários e didáticos tendo como público alvo crianças surdas. Pretendemos explorar aspectos da verbo-visualidade em materiais literários e digitais. O minicurso será desenvolvido com atividade prática de tradução coletiva e registrado em vídeo emergindo da interação a reflexão teórico-prática, colaborando assim para a formação de tradutores e professores de Libras.

Tabela 1: Descrição do minicurso

- Participantes: 25 alunos do curso Letras Libras, surdos e ouvintes proficientes em Libras e uma professora ministrante do minicurso.

- Corpus9: Utilizamos o livro "O pequeno Príncipe", texto base da tradução. Especificamente um trecho do livro traduzido coletivamente.

- Procedimento de coleta de dados: vídeo gravação em sala de aula e diário de campo da professora-pesquisadora, computando quatro horas de gravação. 
- Procedimento de apresentação dos dados: o evento interativo em Libras foi narrado em terceira pessoa, a fim de contextualizar as enunciações e o processo de construção de sentidos dos participantes. A tradução foi apresentada em tabela com texto de partida (Português) e texto da tradução (a Libras foi apresentada em glosas, utilizando-se de transcrição com base em Felipe (2005) e imagens do corpo do sinalizador, disponibilizando-se o link do vídeo para visualização no YouTube). Para as escolhas lexicais, apresentamos os sinais e respectivos links de vídeos em nota de fim.

- Procedimento de análise dos dados: a partir dos eventos interativos, elucidamos o processo dialógico marcado pela alteridade da palavra do outro.

\section{Tradução coletiva como atividade propulsora da forma- ção de TILSP}

A aplicação do método de tradução coletiva revela o processo de tradução em que, a cada nova etapa da leitura, o texto em Libras vai se reconstruindo, onde os participantes vão tecendo novos modos de enunciar em Libras. Os sentidos vão se descamando, coletivamente vão construindo a compreensão do texto de partida [TP] e a expressão em Libras, ou seja, do texto traduzido [TT]. Nesse método todos os participantes podem intervir, opinar, contribuir para a compreensão e para a expressão dos textos envolvidos na tradução, configurando-se em uma aula dialogada e colaborativa a partir do de um trecho do livro de "O Pequeno Príncipe" (figura 01).

Para este artigo selecionamos dois episódios da interação coletiva, discutimos na análise duas categorias: 1) Há diferentes formas de dizer a mesma coisa; e 2) Leitura da imagem. 


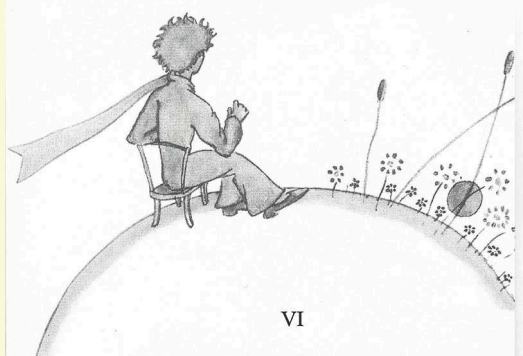

$\mathrm{Ah}$ !, pequeno príncipe, assim eu comecei a compreender, pouco a pouco, os segredos da tua triste vidinha. Durante muito tempo não tiveste outra distração a não ser a doçura do pôr do sol. Aprendi esse novo detalhe quando me disseste, na manhã do quarto dia:

— Gosto muito de pôr do sol. Vamos ver um...

- Mas é preciso esperar.

- Esperar o quê?

- Esperar que o sol se ponha.

Tu fizeste um ar de surpresa e, logo depois, riste de ti mesmo. Disseste-me:

- Eu imagino sempre estar em casa!



24
De fato. Quando é meio-dia nos Estados Unidos, o sol, todo mundo sabe, está se pondo na França. Bastaria poder ir à França num minuto para assistir ao pôr do sol. Infelizmente, a França é longe demais. Mas no teu pequeno planeta, bastava apenas recuar um pouco a cadeira. E, assim, contemplavas o crepúsculo todas as vezes que desejavas...

— Um dia eu vi o sol se pôr quarenta e quatro vezes!

E logo depois acrescentaste:

- Quando a gente está muito triste, gosta de admirar o pôr do sol...

- Estavas tão triste assim no dia em que contemplaste os quarenta e quatro?

Mas o principezinho não respondeu.

VII

No quinto dia, sempre graças ao carneiro, um segredo da vida do pequeno príncipe me foi revelado. Perguntou-me, sem rodeios, como se fosse o resultado de uma longa reflexão:

- Um carneiro, se come arbusto, come também as flores?

- Um carneiro come tudo o que encontra.

- Mesmo as flores que têm espinhos?

- Sim. Mesmo as que têm.

- Então... para que servem os espinhos?

Eu não sabia. Estava ocupadíssimo naquele instante, tentando desatarraxar do motor um parafuso muito apertado. Estava bastante preocupado, pois a pane estava começando

25

Figura 01: Páginas do livro traduzidas no minicurso

Fonte: (SAINT-EXUPÉRY, 2009, p.24-25)

\section{Episódio 1}

Para o trecho da história em que o Pequeno Príncipe confunde-se pensando estar em seu planeta e lembra-se da possibilidade de apreciar o por do sol a todo o momento, o trecho em português: “__ Eu imagino sempre estar em casa!” (SAINT-EXUPÉRY, 2015 , p. 24) foi traduzido da seguinte forma (tabela 2). 




Vídeo disponível em: https://www.youtube.com/watch?v=oBqUjKTHNxs

Tabela 2: Texto de partida e texto da tradução do episódio 1 
Para fim de análise, a interação é narrada a seguir. Inicialmente, o texto foi traduzido por [1sENGANAR EU PENSAR LÁ CASA ${ }^{10}$ ] por um aluno. A professora questionou que casa era aquela? Os alunos responderam que era onde o Pequeno Príncipe vivia, no planeta dele. A professora problematizou: Que planeta era esse? Conduzindo os alunos à reflexão de que o planeta é um planeta pequeno e que na história o personagem não tem uma casa com telhados. Suscita novas formulações, advinda do participante a frente da sala que sugere alterar a tradução para [1sENGANAR EU PENSAR LÁ PLANETA $\left.{ }^{11}\right]$. Então, a professora complementa a tradução sugerindo a alteração da forma do sinal com a diminuição do número de dedos que se movimentam para a produção do sinal [PLANETINHA ${ }^{12}$ ], indicando que por ser um planeta pequeno, poderia ser produzido com três dedos apenas. O professor é um orientador nesse processo e precisa aguardar a expressão dos alunos, a reformulação, conduzindo-os a analisar as versões construídas da tradução e as possibilidades de expressão na língua da tradução. Fontana (2000, p. 38) corrobora nossa análise quando afirma:

O grande desafio foi, e penso que continua sendo, em qualquer trabalho educativo, aprender a esperar o movimento do outro, o seu tempo de elaboração, e a respeitar as elaborações desse outro... Resistir à tentação de impor o caminho que pareça melhor, não só aos nossos próprios objetivos, mas também para o(s) outro(s). E, nesse jogo, a busca do equilíbrio entre evitar a imposição de autoritarismos, sem resvalar para uma postura de falsa neutralidade diante das contradições observadas. (FONTANA, 2000, p. 38).

Logo, um participante argumentou que os surdos podem abstrair o sinal [CASA] como o lugar em que se vive, onde se mora. Apesar de alguns colegas concordarem, contra-argumentaram que muitas crianças surdas passam por atraso de aquisição de linguagem e talvez não tenham interlocutores em Libras para discutir 
sobre o livro traduzido, sendo melhor escolher um sinal mais específico para o sentido do texto e não esperar que o leitor potencial (criança surda) faça a abstração para essa parte da história.

A partir dessa discussão, alguns participantes sugeriram acrescentar o sinal [VIVER] à frase, completando o sentido de morar, de habitar. Parece-nos que não ficou tão claro qual seria a melhor estrutura gramatical, se [1sENGANAR EU PENSAR LÁ VIVER PLANETINHA/ ou /1sENGANAR EU PENSAR VIVER LÁ PLANETINHA].

A reflexão coletiva sobre o escrito em português, língua de partida da tradução, nada mais é que uma prática pedagógica de refinamento do letramento, no âmbito acadêmico, pautada na aula dialogada, no estudo dos textos paralelos ${ }^{13}$, os quais o sujeito (aluno) já conhece ou com aqueles os quais desconhece, permitindo, portanto sua inserção nas esferas do trabalho do tradutor.

Ao final, foi decidido, coletivamente, pela forma [1sENGANAR EU PENSAR VIVER LÁ PLANETINHA] por uma questão estética, considerando que ao executar o sinal [LÁ] e [PLANETINHA] mais distante do corpo do enunciador se indicaria o outro espaço do planeta.

Logo isso decidido, uma participante sugere que ao invés de usar [PLANETINHA], usemos [iPEQUEN@k] (com dedos indicador e polegar distendidos, e movimento $\mathrm{i}=$ ponto próximo à $1^{\mathrm{a}}$ pessoa para $\mathrm{k}=$ pontos próximos à $3^{\mathrm{a}}$ pessoa), como se dissesse em um lugar pequeno e distante, pois o sinal [PLANETINHA] produzido com três dedos "quebraria" a configuração de mão e poderia ocasionar uma dificuldade de compreensão, sugere a seguinte tradução [1sENGANAR EU PENSAR VIVER iPEQUEN@k].

Dois alunos, que estão à frente, não concordam e dizem que [iPEQUEN@k] não se refere ao planeta especificamente, e deixar a interpretação do conteúdo para inferência da criança surda não seria uma boa opção, indicam ser necessário explicitar o que estaria pequeno e longe. Outro participante sugere que se coloque a imagem do planeta ao fundo do tradutor, assim a criança poderia associar a imagem à expressão em Libras. Contudo, essa ideia não 
é aceita por todos, os quais argumentam que alguns elementos precisam estar explícitos na Libras; inclusive um participante expõe: "A Libras tem poder". Outro aluno ainda contrapõe que poderiam sim criar um sinal para o planetinha do príncipe, como se fosse o nome em Libras para o asteroide B 612 (planeta do Pequeno Príncipe), assim como tinham pensado em fazer o sinal de planeta apenas com três dedos em movimento e não com os cinco dedos.

A professora toma a palavra e considera ser possível o entendimento do interlocutor, ponderando que o leitor também fará a leitura da imagem e do contexto da história. Lembrando que, antes um pouco, na história, o narrador disse [OUTRO PLANETA]. Acrescenta que o tradutor não pode ter medo de ousar, de brincar com a língua, é preciso construir uma expressão natural na língua. Um aluno menciona que o importante é a compreensão e a professora concorda.

Então, a discussão toma a direção de refletir sobre as diferentes formas de dizer e a busca pela forma mais adequada para o público alvo, que o tradutor precisa fazer escolhas e ponderar os aspectos envolvidos (contexto do livro, formas de sinais que já foram usados na história, imagens do livro, público a que se destina o material traduzido - mesmo que hipoteticamente). De qualquer forma, casa significa o planeta em que o pequeno Príncipe vivera, porquanto conduz os alunos a fazer uma tradução pelo sentido.

O trabalho de tradução coletiva, como atividade didática de formação, compreende que o tradutor constitui-se na tessitura dialógica; pressupõe que o tradutor, no papel de leitor, possui seu próprio "texto", uma leitura própria marcada por seu contexto histórico e social; pressupõe também que esse deixa de ser um simples receptor passivo para tornar-se um agente atuante no diálogo que se estabelece na resultante produção do significado, de maneira que a aula é conduzida por meio da interação entre os participantes, independente do nível linguístico em ambas as línguas (Português e Libras). Não há um texto previamente traduzido, não há um modelo a seguir. O professor provoca a reflexão e, a todo momento, é desafiado pelos alunos a pensar e repensar a tradução. 
Baseados na perspectiva enunciativo-discursiva - Bakhtin -, conduzimos o processo formativo de tradução fazendo, traduzindo junto com os alunos, refletindo, movendo-se para a compreensão e para enunciação em ambas as línguas, tanto do texto de partida, do texto da tradução, quanto do uso da metalinguagem, para se chegar a um consenso sobre a forma de traduzir, "considerando todo 'texto literário' não como um significado fixo, mas sim como um diálogo que resulta da intersecção de vários planos textuais: do escritor, do leitor, do contexto cultural e histórico em que se processa o ato da leitura" (KRISTEVA, 1986, p. 36) ${ }^{14}$.

\section{Episódio 2:}

No processo de tradução coletiva, um dos participantes do minicurso ficou com a tarefa de ler e expressar em Libras uma primeira versão para o trecho: "Mas no teu pequeno planeta, bastava apenas recuar um pouco a cadeira. E contemplavas o crepúsculo todas as vezes que desejavas" (SAINT-EXUPÉRY, 2015, p. 24). Essa é a voz do piloto falando com o Pequeno Príncipe, comparando a diferença de tamanho entre os planetas, o pequeno planeta B612 (asteroide) e o planeta Terra. Sendo traduzido da seguinte forma (tabela 3). 
Trecho do livro em português [texto de partida]:

Mas no teu pequeno planeta, bastava apenas recuar um pouco a cadeira. E contemplavas o crepúsculo todas as vezes que desejavas. . .

Tradução em Libras [texto da tradução]

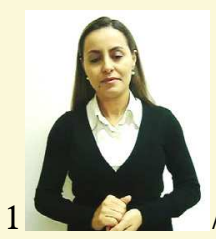

(pausa)

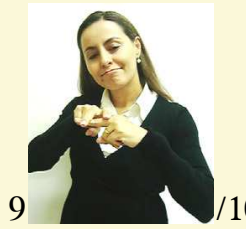

SENTAR

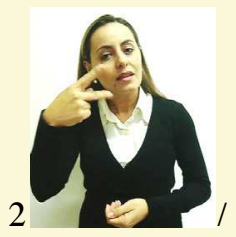

TE@

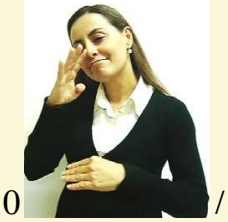

ADMIRAR
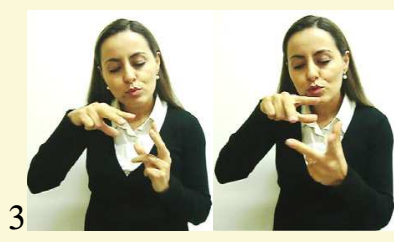

PLANETINHA*
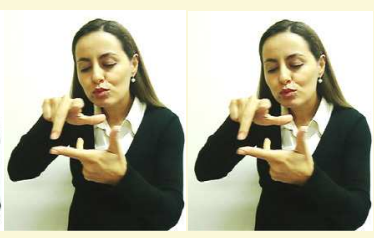

11

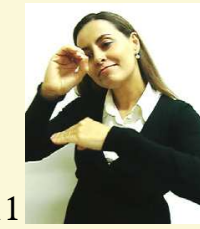

POR-DO-SOL
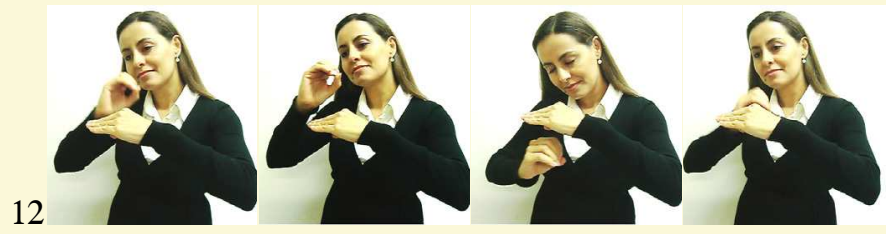

POR-DO-SOL
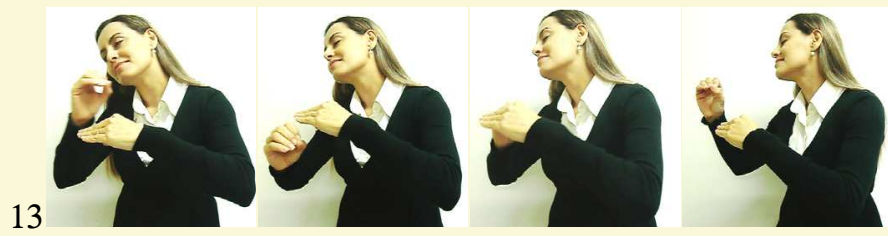

Vídeo disponível em: https://www.youtube.com/watch?v=avJHVICBiLM

Tabela 3: Texto de partida e texto da tradução do episódio 2 
Os textos jamais estão acabados, podendo ser constantemente refeitos pelos que entram em contato com eles (BAKHTIN, 2010). Esse processo requer que se coloquem textos em diálogo. O mundo, cada vez mais, revela-se por meio de narrativas figuradas, exigindo a presença de um novo leitor. Portanto, "a imagem técnica deve ser decifrada para que as diversas camadas de significado nela contidas possam emergir no discurso em forma de texto. Compreender uma imagem é poder percorrer, no sentido inverso, o caminho de seu processo de criação" (SOUZA, 2007, p. 79).

A imagem colabora para a sensibilização do olhar do leitor no processo de construção de sentidos. O tradutor, como um leitor em especial, também desenvolve esta leitura. Faz-se fundamental o diálogo entre ilustração e texto na literatura infantil (DEBUS, 2013). Contudo, em uma primeira leitura, um participante enuncia: [TE@ PLANETINHA SENTAR ADMIRAR VER(me-md) AS-VEZES VONTADE CREPUSCULO ${ }^{15}$ ]. Nessa ocasião, a professora perguntou o que significava a crepúsculo. Os participantes responderam que é o sol se pondo, o dia escurecendo. Então, a professora retomou nos slides a imagem do livro e ilustrações paralelas (figura 2), como também os diferentes textos em português.



Fonte: Ilustração do autor do livro "Pequeno Príncipe" (página 24). 

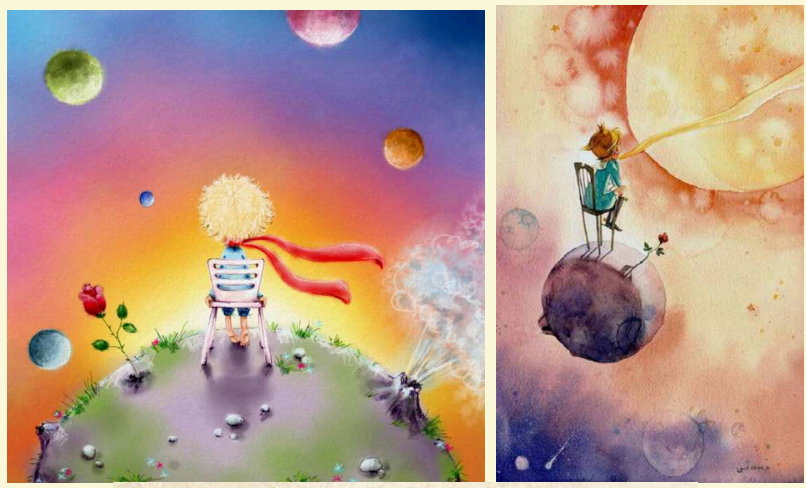

Fonte: http://nerdgeekfeelings.com/2014/12/11/literatura-antoine-de-saint-exupery-para-a-crianca-que-nunca-deixou-de-existir/

Figura 2: Imagens do Pequeno Príncipe (ilustrações paralelas)

Novamente, recorrendo a textos paralelos para buscar compreender o contexto do trecho do livro, indica aos tradutores em formação o papel da pesquisa. São outras leituras que dialogam com o texto do autor, configurando um tecer intertextual para construção do novo texto do tradutor, ou seja, da tradução.

$\mathrm{Na}$ busca por referências em textos paralelos, evidenciamos, cada vez mais, a complexa relação intersemiótica, ou seja, vários modos estão envolvidos em um evento comunicativo e todos os mo- 
dos coadunam para conduzir o interlocutor no sentido do texto. O tradutor precisa mais ainda estar atendo a todos os aspectos, a fim de construir um sentido razoável. Essa dinâmica de aula evidencia a reflexão e a "análise de um processo interacional em que se observam características da constituição heterogênea da linguagem como atividade responsiva" (CORRÊA Di FANTI, 2003, p. 95).

O crepúsculo não é simplesmente o escurecer ou anoitecer. Este termo no livro está relacionado ao momento de se apreciar o por do sol, do por do sol visto na linha do horizonte, significa um momento de contemplação. Assim, está representado em todas as imagens sobre esse trecho pesquisadas e nos textos em português que foram apresentados por diferentes traduções e publicados, como exposto abaixo:

Mas no teu pequeno planeta, bastava apenas recuar um pouco a cadeira. E, assim, contemplavas o crepúsculo todas as vezes que desejavas... (SAINT-EXUPÉRY, AGIR, 2009, p. 24 - Tradução de Dom Marcos Barbosa).

Mas em seu diminuto planeta, meu pequeno príncipe, bastava mover a cadeira alguns passos para a frente, e você já podia contemplar o crepúsculo todas as vezes que desejasse... (SAINT-EXUPÉRY, Autêntica, 2015, p. 25 Tradução de Gabriel Perissé).

Mas, em seu planeta tão pequeno, era só puxar a cadeira alguns palmos. E você olhava o crepúsculo sempre que quisesse (SAINT-EXUPÉRY, L\&PM, p. 27, Tradução de Ivone C Beneditti,).

Pois é. No seu pequeno planeta, é só você afastar um pouquinho a cadeira para ver o crepúsculo toda a vez que quiser. (SAINT-EXUPÉRY, AGIR, p.09, Tradução e adaptação de Geraldo Carneiro e Ana Paula Pedro).

Porém, em seu pequeno planeta basta apenas recuar um pouco a cadeira para contemplar o crepúsculo toda vez que deseje... (SAINT-EXUPÉRY, Geração, 2015, p. 35 Tradução de Frei Betto). 
Alguns alunos ficaram impressionados como poderiam as traduções distinguir-se tanto. Discutiu-se com os alunos sobre a subjetividade envolvida no processo de tradução e o tradutor como um leitor especial que constrói sentidos sobre o texto dialogicamente e marca definitivamente o texto traduzido.

Então, trabalhou-se com os textos paralelos ${ }^{16}$ em imagens, filmes, biografia, traduções do livro para o português e textos sobre o livro e sobre os filmes. Todas essas informações contribuem para uma "leitura" (interpretação). Constatamos, pelos relatos dos participantes, não estarem eles acostumados a esse letramento multimodal, não o vivenciado na escola, que prioriza a análise da escrita, e pouco, ou muito superficialmente, explora aspectos dos outros modos, como a imagem, as cores, o design e tipos de fontes.

Por conseguinte, pontuamos que cursos de formação de tradutores e intérpretes precisam trabalhar o letramento multimodal, buscando adequar-se às novas materializações dos textos contemporâneos, incorporando textos dos mais variados gêneros híbridos em suas atividades pedagógicas (literatura infanto-juvenil, texto publicitário, histórias em quadrinhos, charges, vídeos multimídia, entre outros), nos quais notamos com mais facilidade a relação intersemiótica.

Então, a partir do questionamento da professora, os participantes passaram a enunciar que seria melhor usar o sinal de [POR-DO-SOL ${ }^{17}$ ] e espacialmente direcionar o olhar do personagem para o sol, além de explicitar a linha do horizonte com a outra mão, ficando acordado entre os participantes da aula o sinal de [POR-DO-SOL]. Quanto e como a imagem nutre o repertório visual para construção de cenários e espaços mentais no texto traduzido? Evidenciamos que no processo de tradução, o tradutor é um leitor que traz toda uma bagagem de experiências prévias, de motivações, inserido em um contexto social e cultural e essa individualidade marca a tradução. Nesse contexto, as ilustrações do livro são lidas e nutrem significativamente a enunciação em Libras - texto traduzido.

$\mathrm{O}$ cotejo entre diferentes formas de dizer no texto traduzido dos participantes (alunos); da discussão em sala de aula; das "pro- 
vocações" e da proposta de elementos para o texto traduzido pela professora; dos textos traduzidos em português e da pesquisa por imagens da história ampliam significativamente a compreensão do complexo processo do fenômeno tradutório.

Refletimos que a tradução, a partir da interação analisada, está envolvida do princípio da leitura multimodal, examinando na palavra e nas ilustrações motivadoras da enunciação em Libras (língua da tradução), e aplica-se ao processo de tradução de literatura infanto-juvenil. A interação multimodal em aula dialogada também favorece a forma que o texto traduzido toma com a contribuição coletiva.

O pensamento de Bakhtin destaca as propriedades dialógicas dos textos, sua intertextualidade, na concepção de que qualquer texto está intertextualizado em uma cadeia de texto, isto é, mantém relações de reação, de incorporação e de transformação com outros textos (KRISTEVA, 1986).

A professora conduziu como se traduzir em um meio multimodal e os alunos foram aprendendo que desenvolver uma leitura ampla e ater-se para a produção de sentido é muito mais importante do que saber sinais e fazer uma correspondência palavra-sinal. Recriar os efeitos de sentido dos termos "casa", "planeta" e "crepúsculo"; desvendando as camadas semióticas do material original, congregando as informações verbais e não-verbais, foi um pouco do que os participantes experienciaram nos dias de minicurso de tradução de literatura infanto-juvenil.

\section{Considerações finais}

Os estudos de multimodalidade e tradução intersemiótica criticam o emprego de teorias antiquadas que desconsiderem a linguagem não verbal associada à linguagem verbal. Vivenciamos, em processo de formação de tradutores, a reflexão do quanto o tradutor precisa estar sensível para as diferentes linguagens e para a construção da intertextualidade. 
Em síntese, nestes dois episódios de interação em sala de aula, constatamos que para as escolhas em Libras considerou-se um estilo de Libras natural de interação, escolheu-se formas mais neutras (escolhas lexicais), analisou-se as ilustrações do livro e de textos paralelos, observou-se layout ou formato do texto de partida, criou-se nome culturalmente específico (nome do planeta).

No processo de aula dialogada, utilizando o método de tradução coletiva, vivenciamos o significado das palavras sendo gerados a partir do encontro entre os sujeitos, do enunciado (autor), do ilustrador (desenhista), do receptor - o eu que desenvolvo um processo ativo de contrapalavra (do diálogo travado mentalmente diante da palavra apresentada por nosso interlocutor, da oposição à palavra de outrem). Em síntese, do eu em relação aos pares no diálogo sobre a compreensão e expressão nas línguas.

Essa dinâmica de aula evidencia o processo de construção da tradução, o movimento, e o quanto esse diálogo apresenta possibilidades transformadoras para os sujeitos envolvidos, tanto professor quanto alunos.

Nesse contexto, a definição do termo tradução - que tradicionalmente se referia à versão escrita de uma língua para outra - foi desafiada. E os tradutores precisam estar preparados para trabalhar com um texto multimodal apresentado em diferentes suportes multimídia, bem como para que seus corpos, como texto, sejam incorporados no todo multimodal (produto final).

Com a popularização de artefatos tecnológicos, como o computador e dispositivos móveis, novas formas de registrar a literatura em Libras pela tradução estão sendo desenvolvidas. Esse tipo de gênero discursivo torna-se cada vez mais popular na educação de surdos, oportunizando novas experiências estéticas, o que requer um estudo aprofundado do texto em Libras materializado pelo corpo do tradutor para compor um texto multimodal, como também das diferentes formas interativas de E-books a serem desenvolvidos em Libras, adentrando aos aspectos da educação de surdos, da acessibilidade à literatura, e do ensino e/ou aquisição de linguagem (Libras e Português por escrito). 
É preciso estudar questões referentes à literalidade do texto, à qualidade estética da tradução, à criatividade do tradutor, à voz do tradutor no texto traduzido, à presença do lúdico, pensando em seu destinatário, geralmente crianças.

\section{Notas}

1. Projeto "Videolibros Virtuales" disponível em: http://www.videolibroslsa. org.ar/

2. Informações sobre "Bilingual Storybook App" disponível em: http://www. gallaudet.edu/news/blue_lobster_app.html

3. O termo verbo-visual remete conceitualmente ao linguístico e não linguístico coadunando a enunciação materializada. Poderia causar estranheza empregar este termo para o estudo de línguas de sinais, considerando que elas são de modalidade gestual-visual e de cunho linguístico, pois são línguas. Todavia, pesquisadores de línguas de sinais têm o empregado compreendendo que a porção verbal refere-se à língua de sinais (linguística) e o termo visual refere-se a outras linguagens que co-ocorrem ao processo de sinalização colaborando para a construção de sentidos dos sujeitos em interlocução. Assim, "o verbal também é visual, tal como a língua escrita também é. No entanto, a visualidade da língua de sinais possui sua especificidade por ser, além de visual, gestual" (NASCIMENTO, 2014, p.220).

4. Subtilling significa legenda e surtitling legenda sobre a legenda. 'Legenda sobre a legenda' seria usado no caso em que o personagem enuncia em outra língua que não a do filme o que requer uma legenda com a tradução para a língua usada no filme. Quando esse filme, como um todo, é traduzido, é utilizada uma legenda com a tradução sobre a legenda original. Não encontramos em português um termo para esse fenômeno.

5. 1. Multimedial texts (in English usually audiovisual) are conveyed by technical and/or electronic media involving both sight and sound (e.g. material for 
film or television, sub-/surtitling), 2. Multimodal texts involve different modes of verbal and nonverbal expression, comprising both sight and sound, as in drama and opera, 3. Multisemiotic texts use different graphic sign systems, verbal and non-verbal (e.g. comics or print advertisements, (...), 4. Audiomedial texts are those written to be spoken, hence reach their ultimate recipient by means of the human voice and not from the printed page (e.g. political speeches, academic papers) (SNELL-HORNBY, 2006, p.85).

6. "[...] the problems do not depend on the source text itself, but on the significance of the translated text for its readers as members of a certain culture, or of a sub-group within that culture, with the constellation of Knowledge, judgement and perception they have developed from it" (SNELL-HORNBY,1988, p. 42)

7. O termo em inglês é 'screen tranlation', desenvolvemos uma tradução literal para referir-se a associação do termo tradução com a tela (equipamento eletrônico), sem nos comprometermos em buscar outro termo em português considerando que o propósito da discussão aqui desenvolvida é do termo em si.

8. "At the same time, this terminological indecision might be a sign of vitality, reflecting recent technological developments" (GAMBIER, 2008, p. 25).

9. Chama-se corpus, no plural corpora, o conjunto de textos utilizados em pesquisas linguísticas e de tradução.

10. Forma prototípica de sinal em Libras para CASA Vídeo disponível em: https://www.youtube.com/watch?v=v87W-JdY1yU

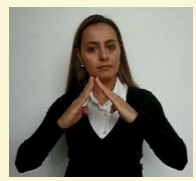

11. Forma prototípica para se referir à PLANETA ou MUNDO em Libras Vídeo disponível em: https://www.youtube.com/watch?v=-sOAyQ15AyM

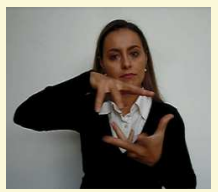


12. Forma criada para e referir ao Planeta B612 (asteroide) em que o Pequeno Príncipe vivia , como um /PLANETINHA/. Vídeo disponível em: https://www. youtube. $\mathrm{com} /$ watch? $\mathrm{v}=7 \mathrm{ryPy}$-nhr9E

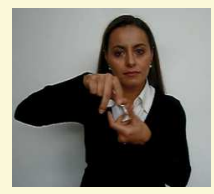

13. Textos paralelos são textos pesquisados pelo tradutor para colaborar com a compreensão de conteúdo específico, textos de assunto similar ao que está trabalhando na tradução. Há também a possibilidade de usar traduções paralelas, ou seja, buscar traduções sobre textos do mesmo assunto para verificar as estratégias e escolhas tradutórias de outros tradutores. A linguística de corpus tem contribuído significativamente com o trabalho de tradução, na medida compila um corpus paralelo composto por textos originalmente escritos na lingua de partida, e por suas respectivas traduções, na língua da tradução.

14. '[...] his conception of 'literary word' as an intersection of textual surfaces rather than a point (a fixed meaning), as a dialogue among several writing: that of the writer, the addressee (or the character) and the contemporary or earlier cultural context" (KRISTEVA, 1986, p. 36).

15. Produção do sinal em Libras para CREPÚSCULO Vídeo disponível em: https://www.youtube. $\operatorname{com} /$ watch? $\mathrm{v}=\mathrm{qTgIV} 3$ id6zI
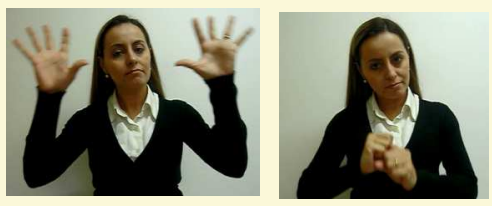

16. Pesquisas apontam para a importância de um trabalho de tradução pautado no diálogo e na observação do léxico por meio de corpus paralelo. "A elaboração de corpora paralelos, por exemplo, contendo TPs [textos de partida] e TTs [textos traduzidos] ou um TP e vários TTs e os comentários sobre os TTs viabilizam a aprendizagem de repertório linguístico pelo tradutor aprendiz" (ROCHA; ALVAREZ; ORENHA-OTTAIANO, 2013, p126). 
17. Forma em Libras para o sinal CREPÚSCULO Vídeo disponível em: https:// www.youtube.com/watch? $v=$ pVc00To91DY


\section{Referências}

ABRALIC. Revista brasileira de literatura comparada. - N. 1 (1991) - Rio de Janeiro: Abralic, 1991. Disponível em: < http://www.abralic.org.br/download/ revista/Revista_Brasileira_de_Literatura_Comparada_-_04.pdf $>$. Acesso em: 10 jun. 2015.

ALBRES, Neiva de Aquino. O espaço do tradutor em material bilíngue (videolivro): uma análise verbo-visual. In: Anais do IV Congresso Brasileiro de Pesquisas em Tradução e Interpretação de Língua Brasileira de Sinais e Língua Portuguesa. Florianópolis - SC: UFSC. 12 a 14 de novembro de 2014. Disponível em: < http:// www.congressotils.com.br/anais/anais2014.html > . Acesso em: 10 dez. 2014.

ALBRES, Neiva; NASCIMENTO, Vinícius. Currículo, ensino e didática em questão: dimensões da formação de tradutores/intérpretes de língua de sinais. Caderno de Letras, $\mathrm{n}^{\circ}$ 22, Jan-Jul - 2014.

ALVES, F., MAGALHÃES, C. e PAGANO, A. Traduzir com autonomia: estratégias para o tradutor em formação. São Paulo: Contexto, 2007.

ARROJO, Rosemary. Tradução, (in)fidelidade e gênero num conto de Moacyr Scliar. Rev. Brasileira de Linguística Aplicada, v. 4, n. 1, 2004. Disponível em: <www.scielo.br/pdf/rbla/v4n1/03.pdf>. Acesso em: 20 abr. 2015 
AZENHA JUNIOR, João. Dependências, assimetrias e desafios na tradução para a criança e o jovem no Brasil. In: SCHEYERL, Denise; RAMOS, Elizabeth (Org.). Vozes Olhares Silêncios: diálogos transdiciplinares entre a linguística aplicada e a tradução. Salvador: EDUFBA, 2008.

BAKHTIN, M. [1929] Marxismo e Filosofia da Linguagem. 6. ed (trad. Michel Lahud e Yara Frateschi Vieira). São Paulo, Hucitec, 1999.

BAKHTIN, M. Estética da criação verbal. (Trad. Paulo Bezerra). 4. ed. São Paulo: Martins Fontes, 2010.

BASSNETT, Susan. Estudos da Tradução. (Trad. de Vivina de Campos Figueiredo). Lisboa: Fundação Calouste Gulbenkian, 2003.

BEARNE, Eve; WOLSTENCROFT, Helen. What are multimodal texts. In: Visual approaches to teaching writing. London: SAGE, 2007. Disponível em: $<$ http://www.sagepub.com/upmdata/14403_Bearne_Wolstencroft.pdf $>$. Acesso em: 12 jan. 2011.

BRAIT, Beth. Ironia em perspectiva polifônica. São Paulo - Campinas: Universidade Estadual de Campinas. 1996.

. Linguagem e identidade: um constante trabalho de estilo. Trabalho, Educação e Saúde, 2(1): 185-201, 2004.

. Olhar e ler: verbo-visualidade em perspectiva dialógica. Revista Bakhtiniana. São Paulo, 8 (2): 43-66, Jul./Dez. 2013. Disponível em: http://www. scielo.br/pdf/bak/v8n2/04.pdf Acesso em: 12 abr. 2015.

CAMPOS, Geir. O que é tradução? São Paulo: Brasiliense, 1986.

CORRÊA Di FANTI, Maria da Glória. A linguagem em Bakhtin: pontos e pespontos. Veredas - Rev. Est. Ling, Juiz de Fora, v.7, n.1 e n.2, p. 95-111, jan./ dez. 2003. Disponível em: http://www.ufjf.br/revistaveredas/files/2009/12/artigo32.pdf 
DEBUS, Eliane Santana Dias. A literatura infantil contemporânea e o diálogo entre ilustração e texto. Resenha. Letras em Revista. v. 05, n. 02, 2014. Teresina: Mestrado Acadêmico em Letras, 2013.

DIONISIO, Angela Paiva (org.). Multimodalidades e leituras: funcionamento cognitivo, recursos semióticos, convenções visuais. Recife: Pipa Comunicação, 2014. Disponível em: < http://pibidletras.com.br/serie-experimentando-teorias/ ET1-Multimodalidades-e-Leituras.pdf > . Acesso em: 10 mai. 2015.

FELIPE, Tânia Amaral. LIBRAS em Contexto. Rio de Janeiro: FENEIS, 2005.

FERNANDES, Célia Regina Delácio. Leitura, literatura infanto-juvenil e educação. Londrina: Eduel, 2013.

FIGUEIREDO, Luciana Cabral. GUARINELLO, Ana Cristina. Literatura infantil e a multimodalidade no contexto de surdez: uma proposta de atuação. Santa Maria. Revista Educação Especial (UFSM), v. 26, n. 45, p. 175-192, jan./abr. 2013. Disponível em: < http://www.ufsm.br/revistaeducacaoespecial > . Acesso em: 12 abr. 2015.

FONTANA, Roseli Cação. Mediação pedagógica na sala de aula. Autores Associados, 2000.

GAMBIER, Yves. Recent developments and challenges in audiovisual translation research. In: CHIARO, Delia; HEISS, Christine, BUCARIA, Chiara. Between Text and Image: Updating Research in Screen Translation. John Benjamins B.V.. 2008. (Benjamins Translation Library).

GERALDI, João Wanderley. Bakhtin tudo ou nada diz aos educadores: os educadores podem dizer muito com Bakhtin. In: FREITAS, Maria Teresa de Assunção. Educação, arte e vida em Bakhtin. Belo Horizonte: Autêntica 2013.

GESUELI, Zilda Maria; MOURA, Lia de. Letramento e surdez: a visualização das palavras. ETD - Educação Temática Digital, Campinas, v.7, n.2, p.110-122, jun. 2006. pp.110-122.

JAKOBSON, Roman. [1959] Aspectos linguísticos da tradução (trad. Izidoro Blinkstein e José Paulo Paes). In: Linguística e comunicação. São Paulo, Cultrix, 1972. 
KRISTEVA, Julia. Word, Dialogue and Novel. In: MOI, Toril (Org.). The Kristeva Reader. Nova Iorque: Columbia University Press, 1986. pp. 34-61. Disponível em: <http://faculty.georgetown.edu/irvinem/theory/Kristeva-Word-Dialogue.pdf $>,<$ https://archive.org/stream/TheKristevaReader/The\%20Kristeva\%20Reader_djvu.txt $>$

LEMKE, J. L.. Metamedia literacy: transforming meanings and media. In: D. REINKING, D.; LABBO, L.; MCKENNA, M.; KIEFER, R. (Ed.). Handbook of Literacy and Technology: Transformations in a Post-Typographic World. Hillsdale, NJ: Erlbaum, 1998. Pp 283-301. Disponível em: < http://static1.1.sqspcdn. $\mathrm{com} / \mathrm{static} / \mathrm{f} / 694454 / 12425231 / 1306520837823 /$ MetaMediaLiteracy.pdf?token= 6pGlMI433vNZDxihtdJ7WYfxZTc\%3D >

LODI, Ana Claudia Balieiro; HARRISON, K. M. P.; CAMPOS, Sandra R. L. Letramento e Surdez: um olhar sobre as particularidades dentro do contexto educacional. In: LODI, A . B. C.; HARRISON, K. M. P.; CAMPOS, S. R. L.; TESKE, O. (Org.). Letramento e Minorias. Porto Alegre: Mediação, 2002.

MAGAlHÃES, Célia Maria. Percursos das Abordagens Discursivas Associadas à Linguística Sistêmica Funcional. In: VIEIRA, Josenia Antunes (et al.). Olhares em Análise de Discurso Crítica. Brasília: www. cepadic.com, 2009. Disponível em: < http://www.cepadic.com/pdf/Livro\%20Olhares\%20em\%20ADC.pdf>. Acesso em: 10 jun. 2015.

MITTMANN, S. Heterogeneidade e função tradutor. In: Cadernos de Tradução. Florianópolis: UFSC. n. 4, 1999.

NASCIMENTO, M. V. B. Interpretação da língua brasileira de sinais a partir do gênero jornalístico televisivo: elementos verbo-visuais na produção de sentidos. (Dissertação) Programa de Linguística Aplicada e Estudos da Linguagem. São Paulo: LAEL/PUC-SP, 2011.

. Gêneros do discurso e verbo-visualidade: dimensões da linguagem para a formação de Tradutores/Intérpretes de Libras/Português. In: BRAIT, Beth; MAGAlHÃES, Anderson (Org.) Dialogismo: teoria e(m) prática. São Paulo: Terra Cota, 2014.

OFIR, Aguiar B. Abordagens teóricas da tradução. Goiânia: UFG, 2002. 
RAMOS, Clélia Regina. Língua de Sinais e Literatura: uma proposta de trabalho de tradução cultural. Dissertação de Mestrado em Semiologia. Rio de Janeiro, UFRJ, Faculdade de Letras, 1995. Disponível em: < http://www.editora-arara-azul.com. br/cadernoacademico/007_dissertclelia.pdf >. Acesso em: 10 abr. 2015.

REILY, L. H. Imagens: o lúdico e o absurdo no ensino de arte para pré-escolares surdos. In: SILVA, I. R.; KAUCHAKJE, S.; GESUELI, Z. M. (Org.). Cidadania, surdez e linguagem. São Paulo: Plexus. 2003. pp. 161-192.

ROCHA, Celso Fernando; ALVAREZ, Roxana Guadalupe Herrera; ORENHA-OTTAIANO, Adriane. O fantástico traduzido: uma análise baseada em corpus paralelo e reflexões para uma pedagogia da tradução. Desenredo. Revista do Programa de Pós-Graduação em Letras da Universidade de Passo Fundo - v. 9 - n. 1 - p. 125-142 - jan./jun. 2013. pp. 125-142. Disponível em: < http://www.upf. br/seer/index.php/rd/article/view/3541/2345>

ROJO, Roxane. Letramentos digitais - a leitura como réplica ativa. Trabalhos em linguística aplicada. Campinas, 46(1): 63-78, Jan./Jun. 2007. Disponível em: $<$ http://revistas.iel.unicamp.br/index.php/tla/article/view/1850/1445>. Acesso em: 10 jun. 2015.

SAINT-EXUPÉRY, Antoine de. O pequeno príncipe. Tradução Dom Marcos Barbosa. Rio de Janeiro, Editora Agir, 2009.

SAINT-EXUPÉRY, Antoine de. O pequeno príncipe. Tradução Frei Betto. São Paulo: Editora Geração, 2015.

SANTOS, Z. B. A construção de uma leitura multimodal em língua estrangeira. Educação em Destaque. Juiz de Fora, v. 1, n. 2, p. 75-86, 2. sem. 2008. Disponível em: <http://www.cmjf.com.br/revista/materiais/1257248917.pdf>

SILVA, Heber de Oliveira da Costa. O tradutor - infiel: a voz da reenunciação. Recife. Dissertação (Mestrado) - Universidade Federal de Pernambuco, CAC. Letras, 2011.

SILVA, João Paulo. Demonstrações em uma narrativa sinalizada em Libras. (Mestrado em Linguística). Faculdade de Filosofia, Letras e Ciências Humanas. São Paulo: USP. 2014. 
SNELL-HORNBY, Mary. Translation Studies: An Integrated Approach. Amsterdam and Philadelphia: John Benjamins Publishing Company. 1988.

SNELL-HORNBY, Mary. The Turns of Translation Studies. New paradigms or shifting viewpoints? Amsterdão e Filadélfia: John Benjamins Publishing Company, 2006.

SOBRAL, Adail. Dizer o mesmo aos outros: ensaios sobre tradução. São Paulo: Special Book. Service Livraria, 2008.

SOUZA, S.J. Dialogismo e alteridade na utilização da imagem técnica em pesquisa acadêmica: questões éticas e metodológicas. In: FREITAS, MT.; SOUZA, SJ.; KRAMER, S. (Org.). Ciências humanas e pesquisa: leituras de Mikhail Bakhtin. São Paulo: Cortez, 2007.

VASCONCELLOS, Maria Lúcia. Tradução e interpretação de língua de sinais (TILS) na pós-graduação: a afiliação ao campo disciplinar "estudos da tradução. In: Cadernos de Tradução. Florianópolis. 2010. v2 n.26 p119-143. Disponível em: < http://www.periodicos.ufsc.br/index.php/traducao/article/view/2175-7968.2010v2n26p119>. Acesso em: $10 \mathrm{dez} .2014$.

VENUTI, Lawrence. Escândalos da tradução: por uma ética da diferença. Trad. Laureano Pelegrin, Lucinéia Marcelino Villela, Marileide Dias Esqueda e Valéria Biondo. Bauru: EDUSC, 2002.

Recebido em: 15/07/2015

Aceito em: 30/09/2015 